\title{
Contribuições da Antropologia Médica a Epidemiologia e a Pesquisa na Área da Saúde
}

Francinete Alves de Oliveira Giffoni ${ }^{1}$; Nayara Luíza Pereira Rodrigues ${ }^{2}$;Nárya Maria Gonçalves de Brito ${ }^{3}$

\begin{abstract}
Resumo: A compreensão da singularidade na percepção da dor e da doença é fundamental para o estudo dos processos envolvidos nos fenômenos pertinentes à saúde humana, quer seja no campo individual ou coletivo. No que tange à epidemiologia e à pesquisa na área da saúde, as generalizações que aparentemente simplificam o trabalho do pesquisador torna-se fonte de viezes que, por vezes lançam uma cortina de fumaça que dificulta uma compreensão mais fidedigna da realidade investigada.
\end{abstract}

Palavras-chave: Antropologia, Epidemiologia, Saúde

\section{Contributions of Medical Anthropology to Epidemiolgy and Research in Health Area}

\begin{abstract}
Understanding the uniqueness in the perception of pain and illness is fundamental to the study of the processes involved in relevant phenomenon to human health, either on an individual or collective field. Regarding the epidemiology and research in health, generalizations that apparently simplify the researcher's work becomes a source of biases that sometimes throw a smoke screen which prevents a more faithful understanding of the investigated reality.
\end{abstract}

Keywords: Anthropology, Epidemiology, Health

\section{Introdução}

Em cada contexto, a análise do adoecimento e da cura, de forma geral, deve levar em conta, primordialmente, a forma diferenciada como o psiquismo de cada indivíduo elabora uma dada situação aparentemente semelhante àquela vivida por outros membros de sua comunidade. A rigidez de uma disciplina, ou a falta dela, por exemplo, podem afetar de maneiras distintas, diferentes pessoas, de acordo com o significado singular que a situação assuma para ela, num determinado período de seu desenvolvimento. Os fatores de risco tem agravos diferentes e individualizados, de modo que, a história particular vivida pelo sujeito, a cadeia de eventos a que esteve exposto ao longo de sua existência e as estratégias construídas para lidar com a realidade, determinam a tonalidade da experiência interior diante do sofrimento, a forma e a intensidade de suas manifestações.

\footnotetext{
${ }^{1}$ Médica Psiquiatra, Doutora em Educação pela Universidade Federal do Ceará. Professora da Faculdade de Medicina da Universidade Federal do Cariri. E-mail: francinete@ufc.br;

${ }^{2}$ Graduação em Enfermagem pela Universidade Regional do Cariri (2008), Especialização em Auditoria em Saúde pela Faculdades Integradas de Patos (2010) e Especialização em Urgência e Emergência pela Universidade Estadual Vale do Acaraú (2014) . Coordenadora de Enfermagem do Polo III do Serviço de Atendimento Móvel de Urgência. E-mail: nayaraluiza28@yahoo.com.br;

${ }^{3}$ Graduação em Enfermagem pela Universidade Regional do Cariri (2008). Atualmente é Doutoranda de Ciências da Saúde da Faculdade de Medicina do ABC-SP. Coordenadora de Enfermagem da UTI do Hospital Regional do Cariri.
} 
Por exemplo: Entrar cedo na universidade, para um sujeito "A" pode significar fator de estresse e tristeza pela perda da liberdade e da descontração, no entanto, para um sujeito "B" pode significar estabilidade, segurança e diminuição do estresse relacionado à incerteza do amanhã.

O resultado observável da experiência depende de ordens internas e categorias psicodinâmicas que articulam os fatores de risco com a forma pela qual o psiquismo do indivíduo elabora e reage. Pode-se observar, por exemplo, pessoas que sofreram agressões na infância encontrarem estratégias internas de superação, gerando a produção de uma rica obra de arte que promove transformações na vida, enquanto em outras, os eventos taumáticos determinam a perda da capacidade produtiva, o isolamento e a depressão, que as limitam, chegando por vezes até à morte. Como se observa nesse caso, a diversidade de manifestações comportamentais relaciona-se às múltiplas possibilidades de significação para cada indivíduo, mesmo dentro do grupo cultural a que ambos pertencem.

Levando em conta essas constatações, a epidemiologia moderna se defronta com uma dificuldade em continuar "simplificando" através da quantificação, os métodos de abordagem e análise de questões pertinentes à saúde humana. Isso porque, diante da diversidade, cada vez maior dos fatores determinantes na etiologia das doenças, torna-se insustentável a premissa de que as populações humanas poderiam continuar a ser consideradas como "grandes massas", onde cada ser, poderia ser representado por um número, e o todo, um conjunto uniforme.

Por essa ótica, a Antropologia médica postula que se promova uma aproximação maior para estudar aspectos inusitados do adoecimento e da busca das práticas de cura. No estudo dos itinerários terapêuticos, por exemplo, aquela população ou amostra, foco da investigação, não é vista simplesmente como a soma de um número de pessoas com características que lhe conferem certa uniformidade como idade, sexo ou condição sócio-econômica. Incluem-se também uma gama de fatores que devem ser observados, considerando a complexidade dos fenômenos, a heterogeneidade dos seres humanos e a multiplicidade de suas dimensões. Nessa perspectiva, dentro de um mesmo grupo populacional costuma-se encontrar uma diversidade de tipos de manifestações e comportamentos, conforme as nuances e situações às quais os indivíduos estejam expostos e, dependendo do momento existencial no qual as experiências são por eles vividas. E, além dos aspectos de individualização das experiências, considera-se os subconjuntos humanos que se formam por meio das interpenetrações de grupos deflagradas pela grande fragmentação social, desestruturação familiar e desigualdade social que aumentam a emergência de novos grupos de risco dentro de um mesmo grupamento humano.

Estudiosos do assunto como SILVA (in CASTIEL:1994, 148) têm considerado dois ramos da epidemiologia: a epidemiologia clínica, que se baseia em estudos controlados acercando-se especificamente dos fenômenos biológicos referentes à saúde e à doença, e a social, que busca observar os múltiplos fatores determinantes do processo saúde-doença em populações, considerando

204 Id en lime Revista de Psicologia. Ano 9, №. 26, Supl. Esp. Abril/2015 - ISSN 1981-1179. Edição eletrônica em http://idonline.emnuvens.com.br/id 
tanto aspectos gerais do grupo quanto as peculiaridades dos indivíduos que o compõem. Essa segunda vertente tem se fortalecido graças a estudos antropológicos que vêm evidenciando novas formas de organização social que estão se plasmando entre os povos. Segundo esses estudos, formamse hoje entre os grandes grupos populacionais, verdadeiras "tribos", com características que as individualizam e diferenciam umas das outras.

Dentro dessa realidade, no campo da saúde, a epidemiologia médica se encarrega de denunciar as reduções e tendenciosidades das teorias hegemônicas que tendem a negligenciar a dimensão histórica do adoecer humano, a relação entre o campo da saúde e o todo social, incluindo as desigualdades sócio-econômicas. Essa vertente, no entanto, vê-se diante do problema de como conceituar e operar com as variáveis do campo social: crenças, comportamentos, percepções, estrutura familiar, hábitos e valores. Além disso, como relacionar todas essas variáveis aos processos mórbidos, aos sinais e sintomas que resultam na expressão clínica das doenças, finalmente transformados em dados estatísticos.

Na visão de Castiel(1994), a partir desse fenômeno, a pesquisa em saúde tem necessitado de avanços teórico-metodológicos a fim de produzir evidências clínicas confiáveis. O autor cita as palavras de Clarice Lispector (in Castiel, 1994, p.171) quando diz que existe "algo" entre o número um e o número dois “(...) Entre dois fatos existe um fato, entre dois grãos de areia, por mais juntos que estejam, existe um intervalo de espaço(...)". Para Castiel, além da questão da pesquisa, políticas eficazes em saúde pública, devem ser pautadas na compreensão da diversidade dos fenômenos humanos, especialmente quando se refere à problemática do "adoecer". Por esse prisma, a doença é uma forma de linguagem, e o estar doente nem sempre equivale ao sentir-se doente. Existe um código interno, único e secreto, através do qual, cada organismo, e cada pessoa pode ou não perceber-se ou mostrar-se doente. Como esses casos deverão figurar no turbilhão de números estatísticos?

Desta forma, o objeto da epidemiologia, conforme Castiel(1994), não mais pode ser constituído pela soma dos determinantes de riscos que incidem sobre grupos populacionais "homogêneos". Pelo contrário, deve basear-se em leis psicológicas e sociológicas, admitindo a manifestação indireta do funcionamento neurocerebral do organismo e suas comunicações, à forma de metáforas. Para MINAYO ( 1998), o modelo da medicina biológica, não mais atende às necessidades evolutivas da epidemiologia, especialmente quando se trata de sua aplicabilidade na saúde coletiva.

Torna-se cada vez mais evidente que a ótica mecanicista não dá conta de conceituar e operar quatitativamente com as variáveis do campo social: crenças, comportamentos, percepções, estrutura familiar, hábitos e valores. Torna-se impraticável a tentativa de relacionar matematicamente todas essas variáveis aos processos mórbidos, aos sinais e sintomas que resultam na expressão clínica das doenças.

Desde meados dos anos 60 a produção acadêmica relacionando antropologia e saúde começa sinalizar para as fragilidades desta abordagem. Canesqui (1993) assinala as recentes contribuições da 
Antropologia americana (Eisemberg, 1977; Kleinmam, 1978; Frankemberg, 1980, Young, 1982) com a categorização dos termos : disease que significa manifestação patológica, conforme o modelo biomédico, illness, que é a resposta subjetiva do paciente, seu mal-estar e sickness, a reação das pessoas que o cercam, a ordem cultural. Nessa perspectiva, a doença é vista como um processo social que envolve todo o círculo de relações do sujeito, sua personalidade, nível econômico e traços culturais. O surgimento desses conceitos naquela época permitiu o aprofundamento no conhecimento de doenças tradicionais e terapias nativas e influenciaram no surgimento da Antropologia Médica, como ramo da Antropologia Geral. Ela nasce associada à clínica e à epidemiologia, em estudos relativos à incidência de doenças, instituições médicas e etnomedicina.

Decorre desses avanços o estudo do sentido simbólico dos sintomas, a resposta emocional aos mesmos e a busca de compreensão dos itinerários terapêuticos em busca de estratégias específicas de cura. No Brasil, até uma década atrás a realidade era essa:

Inexiste ainda institucionalizada no Brasil uma subárea especializada do conhecimento antropológico dedicada ao tema, nos moldes existentes nos Estados Unidos, Inglaterra e de certa forma $\mathrm{s}$ internacionais de saúde pública, dentre eles os dirigidos à América Latina e Brasil, sob forte na França. Nos Estados Unidos, nas décadas de 40 e 50, a Antropologia penetrou os programas de saúde com influência da abordagem funcionalista-culturalista e dos estudos de George Foster e Redfield (CANESQUI, 1993,p. 15)

Na visão de alguns estudiosos brasileiros já se configurava a crescente demanda por estudos que contemplassem aspectos mais complexos da vida social em centros urbanos, incluindo, além dos tabus e crenças associados à alimentação, à gravidez ao parto e puerpério, a problemática dos subgrupos e suas modalidades perceptuais do sofrimento. Uma das alternativas para uma ampliação conceitual e o aprofundamento na problemática do adoecer humano foi buscar o terreno da transdisciplinaridade, na intersecção dos campos epistemológicos da Medicina e da Antropologia. A relação estreita entre estas áreas permite transcender a questão da relação causal perseguida na abordagem do modelo biomédico tradicional.

No Brasil, a V Conferência Nacional de Saúde (1975) promoveu intensa articulação de movimentos de profissionais da área de saúde e pesquisadores em torno dessas temáticas. A partir daí, movimento Sanitário arrefecido pelo fortalecimento de vínculos entre profissionais de saúde e áreas afins, formalizaram diversas análises críticas do sistema de saúde e das políticas públicas das quais resultaram projetos inovadores. Nestas iniciativas, tanto as teorias, como os métodos de pesquisa passaram a ser questionados. O próprio conceito de saúde Coletiva foi revisto, num processo de redimensionamento paradigmático à luz das contribuições das ciências sociais que passam a integrar de forma mais intensa os campos teórico e prático da área de saúde.

A partir dessas mudanças, dentre outros autores, Barreto (1998), Andrade (1999), Alves \& Rabelo (1998) propuseram-se a investigar a influência do contexto social sobre as enfermidades. 
Uchoa e Vidal (1994, p. 499) enfatizaram a grande influência que exercem a semiologia popular e as concepções culturais de causalidade sobre os comportamentos adotados frente às doenças. ALVES e RABELO (1999); HELMAN (1994); LAPLANTINE (1991); LOYOLA (1984); ROCHA (2000); UCHOA e VIDAL(1994) e outros autores, afirmaram em diversos estudos que o conjunto de crenças culturais e comportamentos de um grupo social participa de uma interação multifatorial na etiologia das doenças. As observações dos antropólogos contribuíram para fortalecer esse pensamento e demonstrar que as percepções populares contam como variáveis sociais das doenças e suas predisposições. No campo da saúde coletiva houve repercussão positiva na aceitação de uma abordagem médica que incluísse a perspectiva cultural trazida pela Antropologia. A definição do campo da Antropologia médica veio favorecer a construção de estratégias de ação mais eficazes, levando em conta a teia de significados que envolvem os comportamentos ligados ao adoecimento e à cura.

Esse posicionamento foi bastante incentivado por Helman (1994), que trouxe à luz a importância dos valores e costumes associados à saúde e à doença, enquanto parte do complexo cultural das sociedades humanas. Para ele, numa dada cultura, as formas como as pessoas são reconhecidas como doentes e o modo como apresentam sua doença aos outros, representam a organização social da saúde e da doença naquela população.

Por esse prisma, compreende-se que, para se estudar os fenômenos humanos, nos aspectos objetivos e subjetivos, como, por exemplo, no caso da relação do homem com a saúde e doença, o conhecimento do universo de significações presentes na cultura assume especial importância. Nesse sentido, observa-se que "toda cultura define o universal de forma singular" (Correa 2000, p.61), e que " cada cultura torna possível uma visão de mundo assim como a construção de teorias particulares de seu meio cultural" (p.62). Daí começaram a proliferar estudos fundamentados numa abordagem compreensivo-interpretativa da cultura, utilizando os pressupostos teórico-metodológicos da Antropologia médica e da Etnografia.

A utilização da abordagem etnográfica oferece à pesquisa na área de saúde a possibilidade de se investigar fatores pertinentes aos incidentes da vida cotidiana dos sujeitos, aos "imponderáveis da vida real" (Malinowski, 1984, p.29) como: a rotina de trabalho diário, os detalhes dos cuidados corporais, os hábitos e valores dos indivíduos em seu contexto. Por meio dessa abordagem, a rede social da qual o indivíduo faz parte, os valores culturais de seu grupo, o estilo de vida, suas interrelações e interações com o ambiente, são observados como determinantes na análise dos problemas relacionados à saúde. O objetivo a ser perseguido passa a ser não só o fenômeno do adoecer mas, o ponto de vista de quem sente a dor, seu relacionamento com a vida, sua visão de seu mundo. Nesse sentido, a Antropologia médica vem contribuindo com novas possibilidades de se elaborar modelos compreensivos, que favoreçam uma abordagem interpretativa dos fenômenos, sob o ponto de vista dos atores sociais. 
Existem hoje estudos científicos que abordam temáticas, a um só tempo, pertinentes aos campos da Medicina, da Epidemiologia e da Antropologia. A intersecção destas áreas permite avançar para além da simples correlação estatística e da relação causal perseguidas na abordagem quantitativa da epidemiologia clínica, que se limita a identificar fatores de risco e predisposição ao aparecimento das doenças.

Quando se pretende estudar o sujeito, num enfoque mais individualizado, uma abordagem multifatorial, e, portanto, complexa, mostra-se mais efetiva. Além disso, quando se busca descobrir a ocorrência de doenças mais exóticas, como em certos estudos epidemiológicos especiais, a pesquisa antropológica pode esclarecer de que forma fatores culturais, podem ser determinantes e de que forma estes interagem com os fatores genéticos, biológicos.

\section{A Abordagem Etnográfica e sua importância na Pesquisa em Saúde Coletiva.}

A antropologia moferece, através da abordagem etnográfica, a possibilidade de se investigar fatores pertinentes aos incidentes da vida cotidiana dos sujeitos, aos "imponderáveis da vida real" (Malinowski, 1984:p.29)

(...) a existência de hostilidade ou fortes laços de amizade, as simpatias ou aversões momentâneas entre as pessoas; a maneira sutil, porém inconfundível, como a vaidade e a ambição pessoal se refletem no comportamento de um indivíduo e nas reações emocionais daqueles que os cercam. Todos esses fatos podem e devem ser formulados cientificamente e registrados.

Nessa abordagem, a tarefa é estudar o homem e "tudo aquilo que mais intimamente lhe diz respeito" (...)p.33. Em questões tocantes ao binômio saúde/doença, a Antropologia oferece possibilidades de se elaborar modelos compreensivos, que favoreçam uma abordagem interpretativa dos fenômenos, sob o ponto de vista dos atores sociais. A identificação de condições patogênicas anteriores da história de vida do sujeito, presentes no campo subjetivo, a descrição popular dos agravos à saúde e o sistema de crenças e valores nos quais se inserem são algumas das possibilidades oferecidas pela abordagem etnográfica, no campo da antropologia médica.

$\mathrm{O}$ conceito de multiplicidade diz respeito à variedade, às múltiplas possibilidades de significação do fato de adoecer para um determinado indivíduo e para o grupo cultural a que pertence. A singularidade na percepção traz a questão da diferença de um ser humano para outro ao sentir e expressar o adoecimento e a cura. Nos estudos plasmados nos moldes da Antropologia da saúde, quando se aborda a dor e o sofrimento no ser humano, não se refere apenas à anatomia, fisiologia ou fisiopatologia do quadro sintomatológico que se apresenta. A abordagem é mais aprofundada e ao mesmo tempo, ampliada, buscando códigos secretos, significados íntimos e acontecimentos aleatórios 
que possam, "ao acaso" fazer parte da vida do sujeito podendo gerar diferenças, muitas vezes encontradas entre pessoas com mesma idade, sexo, classe social e mesmos hábitos de vida. As diferenças podem estar relacionadas a uma cadeia de eventos improváveis que ocorreram na história particular daquele sujeito e não de outro, pertencente ao mesmo grupo populacional. Parte-se do pressuposto que cada indivíduo tem efeitos imponderáveis em sua vida, podendo estes efeitos serem negativos ou positivos na situação do adoecimento e da cura.

Considerando ainda que o conjunto de crenças culturais e comportamentos de um grupo social participam de uma interação multifatorial na etiologia das doenças, as observações dos antropólogos vêm contribuir para agregar num mesmo modelo de abordagem, percepções populares que contam como variáveis sociais das doenças e o conjunto de predisposições e peculiaridades individuais e grupais. Pode-se portanto concluir que os atuais avanços conquistados no campo da saúde, do ponto de vista tecnológico e de qualidade dos serviços, somados às mudanças paradigmáticas propostas pela Antropologia médica venham favorecer a construção de estratégias de ação mais eficazes e adequadas a cada ser humano em seu contexto.

\section{Referências}

ANDRADE, J. T. “ Terapias Complementares em Saúde Pública: Alguns Aspectos do Debate Antropológico Contemporâneo" in Humanidades e Ciências Sociais . Revista da Universidade Estadual do Ceará, V.1 . Fortaleza: UECE, 1999 (19-23).

CAMPILONGO, M.A. "Questões Epistemológicas nas Disciplinas da Saúde" in Saúde Coletiva Cadernos de Sociologia, V.7 . Porto Alegre: PPGS-UFRGS, 1995 (5-16).

CASTIEL, L.D. $O$ Buraco e o Avestruz. A singularidade do Adoecer Humano.São Paulo: Papirus, 1994.

HELMAN, C.C. Cultura, Saúde e Doença. Porto Alegre: Artes médicas, 1994.

MALINOWSKI, B. Argonautas do Pacífico Ocidental. Um relato do empreendimento e da aventura dos nativos nos arquipélagos da Nova Guiné Melanésia. São Paulo: Victor Civita, 1984.

MINAYO, M.C.S. O Desafio do Conhecimento. Pesquisa Qualitativa em Saúde. São Paulo Rio de Janeiro: Hucitec-Abrasco, 1996.

ALVES, P. C. B. e RABELO, M. C. M. 1999 Significação e metáforas na experiência da enfermidade. In: RABELO, M. C. M.; ALVES, P. C. B. \& SOUZA, I. M. A. Experiência de doença e narrativa. Rio de Janeiro: Fiocruz. p. 171-86.

HELMAN, C. G. 1994 Cultura, saúde e doença. Porto Alegre: Artes médicas.

LAPLANTINE, F. 1991 Antropologia da doença. São Paulo: Matins Fontes.

LOYOLA, M. A. 1984 Médicos e curandeiros: conflito social e saúde. Rio de Janeiro: Difel. 
ROCHA, R. M. 2000 Trajetórias terapêuticas de usuários de serviços psiquiátricos e adeptos de umbanda: um estudo sobre pluralismo terapêutico. Revista de Enfermagem $U E R J$, v. 8, n. 2, p. 737.

UCHOA, E.; VIDAL, J. M. 1994 Antropologia médica: elementos conceituais e metodológicos para uma abordagem da saúde e da doença. Cadernos de Saúde Pública, v. 10, n. 4, p. 497-504.

\section{Como citar este artigo (Formato ABNT):}

GIFFONI, F.A.O.; RODRIGUES, N.L.P.; BRITO, N.M.G. Contribuições da Antropologia Médica a Epidemiologia e a Pesquisa na Área de Saúde. Id on Line Revista de Psicologia, Abril de 2015, vol.9, n.26, Supl. Esp. p. 203-210. ISSN 1981-1189.

Recebido: 25/01/2015

Aceito:12/02/2015 